University of Warwick institutional repository

This paper is made available online in accordance with

publisher policies. Please scroll down to view the document

itself. Please refer to the repository record for this item and our

policy information available from the repository home page for further information.

To see the final version of this paper please visit the publisher's website. Access to the published version may require a subscription.

Author(s): Tom Wellings, Mark Williams and Charles Tennant

Article Title: Understanding customers' holistic perception of switches in automotive human-machine interfaces

Year of publication: 2009

Link to published version:

http://dx.doi.org/10.1016/j.apergo.2009.03.004

Publisher statement: none 


\title{
Understanding customers' holistic perception of switches in automotive human machine interfaces
}

\section{Authors}

Tom Wellings, Mark Williams, Charles Tennant

\section{Affiliations}

WMG, The University of Warwick, Coventry, CV4 7AL, UK

\begin{abstract}
For successful new product development, it is necessary to understand the customers' holistic experience of the product beyond traditional task completion, and acceptance measures. This paper describes research in which ninety eight UK owners of luxury saloons assessed the feel of push-switches in five luxury saloon cars both in context (in-car) and out of context (on a bench). A combination of hedonic data (i.e. a measure of 'liking'), qualitative data and semantic differential data were collected. It was found that customers are clearly able to differentiate between switches based on the degree of liking for the samples' perceived haptic qualities, and that the assessment environment had a statistically significant effect, but that it was not universal. A factor analysis has shown that perceived characteristics of switch haptics can be explained by three independent factors defined as 'Image', 'Build quality', and 'Clickiness'. Preliminary steps have also been taken towards identifying whether existing theoretical frameworks for user experience may be applicable to automotive human machine interfaces.
\end{abstract}

\section{Keywords}

User-centred design, Haptics, Affective design, Automotive HMI

\section{Introduction}

\subsection{The need for customer knowledge in new product development}

It is often asserted that utilising some form of defined New Product Development (NPD) process - for example, a stage-gate system (Cooper and Kleinschmidt, 1991) - is an important component of product success. It is also a commonly held belief that profitability is dependent on speed to market, the inference being that most effort should be directed towards streamlining the NPD process (Robinson and Min, 2002). Some authors however, challenge this line; emphasising instead that whilst being first to market does have a positive effect on sales volume, introducing a superior product with real advantages for the consumer may be at least as important as correctly judging the time of market entry (Adams-Bigelow and Griffin, 2005; Cooper et al., 2004; Langerak et al., 2008). 
Providing the real product advantages that customers are demanding remains a challenge, despite the acknowledgement that early identification of customers' future needs is a vital stage of new product development (Griffin, 1997; Kahn et al., 2006; Williams and Kochhar, 2000). This may be partly explained by the changing relationship between producers and customers. Where at one time all that a customer desired was for their basic needs to be fulfilled at an affordable cost, now, improved production capability and efficiency has resulted in a huge choice of similar low cost products. This has lead to a shift in power away from the producer toward the customer, leaving corporate leaders with in depth knowledge of how to make things, but not knowing what it is they should make (Kumar and Whitney, 2007). To compound the issue, it has become apparent that using traditional, customer orientated market research techniques is no longer enough to capture new customers (Carbonaro and Votava, 2005). Instead, new approaches are needed which prioritise a deeper understanding of the customer over simple demographics, product feature count and price. Additional considerations should include motivations for product usage, the benefits that the product provides, users' emotional responses to products, and the social context of use (Veryzer and de Mozota, 2005).

If all these factors of product usage are contemplated when developing new products, it means recognising that the subject of customer research is now the holistic 'user experience', and that a different selection of data collection and design methods will be necessary to address this. Practitioners and researchers from a variety of backgrounds have already adopted the term 'user-centred design' (UCD) to describe this process, but currently there is limited consensus on the exact definition of this term, or the theoretical models that underpin 'user experience’ (Jetter and Gerken, 2006).

\subsection{User-centred design: beyond task performance}

Born out of human factors, information technology, and human-computer interaction (HCI) research in the 1970's and 80's, User-Centred Design is often used as an umbrella term for design methodologies that focus on the user in the development process. Traditional human factors takes a system centred approach, where the user or operator is treated as a resource, whose purpose is to control a machine, or artefact (Helander, 1997). In the UCD process however, consideration of users' roles, and overcoming human limitations are the key design objectives (Stanney et al., 1997). More specifically, the processes should involve user participation, and consider criteria for functionality, usability, user acceptance, and organisational acceptance (Eason, 1989). The ISO standard for human-centred design processes similarly defines UCD objectives as "enhancing effectiveness and efficiency, improving human working conditions, and counteracting possible adverse effects of use on human health, safety and performance" (ISO, 1999). What is not included here is a vision of users that goes beyond optimisation, safety and productivity; that is, goes beyond the task-centric roles demanded by technology-led business models to emphasise people in their social context. (DTI, 2004; Krippendorff, 2004b). Despite this historical reliance on functional criteria, it is clear that concerns such as how to design products that are pleasurable to use, and emotionally engaging to interact with are gaining in importance, and appearing more frequently in a wide range of research literature (e.g. Evans and Burns, 2007; Jordan, 2000; Karat and Karat, 2003).

Much of this more recent multi-disciplinary research fits within the wider remit of UCD, although work focussing on the affective and emotional responses from human-product interaction is sometimes more explicitly labelled as 'affective design', or 'affective engineering.' What is clear is that user-centred research methodologies can be broadly divided into two camps. There are those that evaluate products or concepts in an experimental manner (evaluative research), and those that generate understanding through 
techniques developed in the social sciences such as participant observation and ethnography (generative research).

Evaluative studies carried out during new product development frequently use rating scales to measure consumers' attitudes and acceptance of potential new products. These data are then analysed using multivariate statistics in order to try and link product perceptions and overall liking to specific product characteristics. Examples can be found in many diverse areas including automotive interiors (Bonapace, 2002; Karlsson et al., 2003; Khalid and Helander, 2004), telecommunications (Hsu et al., 2000; Yun et al., 2003), cosmetics (Nagamachi, 2002), and food science (Stone and Sidel, 2004). In contrast to these experimental approaches to data collection, generative research emphasises in-depth understanding of consumer behaviour, unmet needs, and the generation of new product ideas (Leonard and Rayport, 1997; Light, 2006). In particular, Light believes that to gather information on someone's motivational and emotional experience with technology it is necessary to use exploratory techniques such as qualitative interviewing or observation of usage.

Underpinning both these rationales are numerous theoretical models and frameworks describing user experience in terms of their perception of the product. At this time there is no unified model that holds true for all interactive experiences, however some commonalities exist between frameworks whereby product attributes are explicitly linked with a user's needs and values, often by means of some measure of hedonic quality (Hassenzahl, 2005). This can be seen in Jordan's hierarchy of user needs (a variation of Maslow's hierarchy of human needs) where 'pleasure with products' is defined as “the emotional, hedonic, and practical benefits associated with products” (Jordan, 2000); it is also seen in Hekkert's framework for product experience (Hekkert, 2006), where the experiential components are identified as aesthetic pleasure, attribution of meaning, and emotional response; and also with Desmet's 'basic model of product emotions' (Desmet and Hekkert, 2007), in which product qualities are appraised as to their fulfilment of personal expectations, goals and motives. As summarised by Hassenzahl and Tractinsky, (2006) one of the principle challenges for future interaction research is to better understand, define and operationalise the user's non-instrumental needs.

\subsection{The importance of haptics to user experience in cars}

As a simple definition, the study of haptics concerns humans' perception of objects through the sense of touch. Many forms of tactile stimuli may contribute to this overall haptic perception, with the resulting experience being valenced positively or negatively to some degree. Conceptually this can be understood as the perception of haptic quality, and although it is recognised that input from all senses will influence the outcome, the focus is on how things 'feel'.

Whilst there has been much research into the visual aesthetics of products, and the importance this plays in a customer's evaluation of a product, there has been much less that has investigated the contribution that haptic quality makes to the user experience. Earlier studies focus on ergonomic questions such as how the shape of push-buttons affects their tactile discriminability (Moore, 1974), whereas more recently, sensory science methods have been used to understand how product haptics are perceived, and also how the tactile properties of certain materials might be characterised (Giboreau et al., 2001; Kawazu et al., 2000). Overall though, tactile qualities have been somewhat undervalued in design, despite being of fundamental importance to the perception of many products by virtue of the physical interaction necessary to use them (MacDonald, 2001). This is now starting to change with the advent of haptic feedback in many mainstream consumer electronics such as mobile phones, video game controllers, and car interface controllers. 
In the case of cars, as the relationship between the driver and the vehicle becomes more complex and multidimensional, the haptic quality of components such as the human machine interfaces (HMI), steering wheel, and gear stick play an increasingly important role in this relationship (Benson et al., 2007). By exploiting these haptic cues, designers and manufacturers can influence the value judgements their customers make, and differentiate their products from their competitors (Burnett and Porter, 2001; Mauter and Katzki, 2003; McLoone, 2003).

The difficulty in a modern automotive NPD process arises when trying to objectively interpret customers' opinions, because in order to make informed decisions and communicate with suppliers, metric data and specifications are necessary. What is needed is a way for automotive manufacturers to evaluate their future HMI along dimensions beyond traditional attributes such as functional performance, and cost. They would like to know if the physical switches used in their HMI will be accepted by customers, and whether components can be designed to more closely reflect their experiential expectations. A key objective of this work has been to provide engineers and designers with more detailed information on customer perception of push-switches than that typically provided by hedonic marketing studies. It is the aim to demonstrate whether customers can notice variations in the haptic quality of HMI, and also to find out if there is any consensus in what these qualities are. By investigating the underlying perceptual dimensions of switch haptics, preliminary steps have been taken towards identifying whether existing theoretical frameworks for user experience may be applicable to automotive HMI. The industrial relevance of the findings has then been verified through their application directly on specific vehicle development programmes with a mass manufacturer of luxury cars.

The research questions can be stated as follows:

- Do luxury automotive saloon customers show a common overall liking and preference for the perceived operational feel of luxury automotive push-switches? Can insights be gained into the homogeneity of the customer sample from an affective viewpoint?

- Is there a difference in the hedonic judgements of switch-feel given when assessed in the context of the branded vehicle interior, compared with assessing unbranded samples out of context on a bench in a controlled environment?

- What are the perceived characteristics of switch haptics that relate most closely to the hedonic responses given by owners and drivers of luxury automotive saloons?

\section{Materials and Methods}

\subsection{Participants and product samples}

Ninety eight UK residents took part in the study assessing the feel of push-switches in five European specification luxury saloon cars, as well as assessing identical switches out of context on a bench for comparison purposes. The participants were recruited by an external agency and were mainly owners or principle drivers of one of the five vehicles whose switches were chosen for the study. The participants, and the five vehicles and automotive switch samples they assessed were chosen to be representative of the 2006 European luxury saloon car market. It was decided to base the sample demographics on European, rather than the narrower UK market data because vehicles destined for countries within the European Union (EU) are governed by common legislation resulting in little end-market variation (VCA, 2001). 
Proprietary market research data from collaborating automotive manufacturers were used to define the sample, and the summary breakdown is shown in Table 1.

Table 1: Summary details of participant sample for the customer event

\begin{tabular}{llrr}
\hline Description & Category & Count & $\begin{array}{r}\text { \% of } \\
\text { Total }\end{array}$ \\
\hline \multirow{3}{*}{ Sex } & Male & 71 & $72 \%$ \\
& Female & 27 & $28 \%$ \\
& Total & 98 & $100 \%$ \\
Age & & & \\
& $35-44$ & 38 & $39 \%$ \\
Vehicle Owned & $45-54$ & 36 & $37 \%$ \\
& V5-64 & 24 & $24 \%$ \\
& Vehicle B & 22 & $22 \%$ \\
& Vehicle C & 21 & $21 \%$ \\
& Vehicle D & 20 & $20 \%$ \\
& Vehicle E & 21 & $21 \%$ \\
& Other & 14 & $14 \%$ \\
\hline
\end{tabular}

a \% rounded to nearest whole number

The assessment focussed on push-switches found in the centre console area of the dashboard. This is where many of the primary driver controls such as heating, ventilation, and infotainment (combined satellite navigation and radio) are found, and is an area of high importance for driver/passenger interaction with the vehicle. Providing detailed data on specific components was a prominent consideration in this study, which is why the decision was taken not to compare the feel of all the switches in the interior (Jindo and Hirasago, 1997).

The vehicle set whose push-switches were to be assessed were specified to have comparable interior trim levels as far as was possible, and were labelled ' $A$ ' to ' $E$ '. The brands were visible, because in the majority of cases, the participants were already familiar with at least one of the models present, and capturing the 'real-life' perception of switch-feel was important. A duplicate set of unbranded standalone switch-packs, identical to those switches assessed within the vehicles were also included in the study. These were labelled with alternative alphabetic labels from the vehicles they came out of in order to reduce the association with the brand. Fig 1 shows the separate samples as assessed in the five vehicles. 


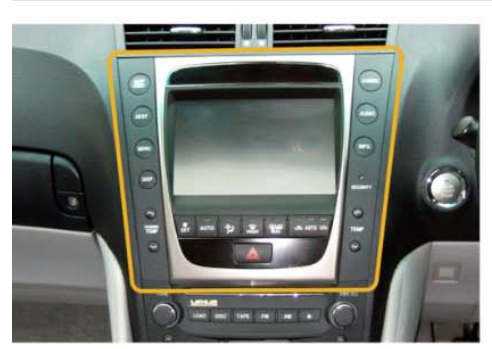

Sample A

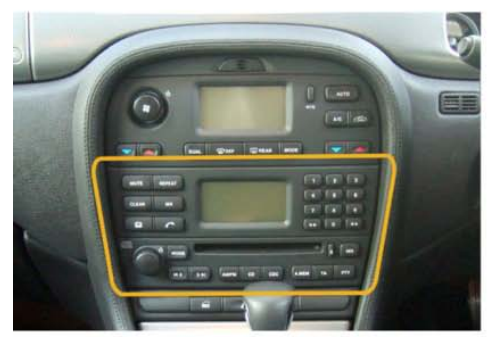

Sample D

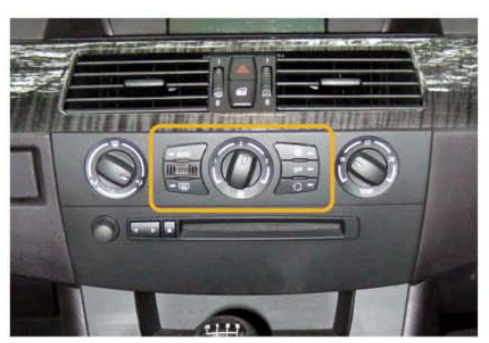

Sample B

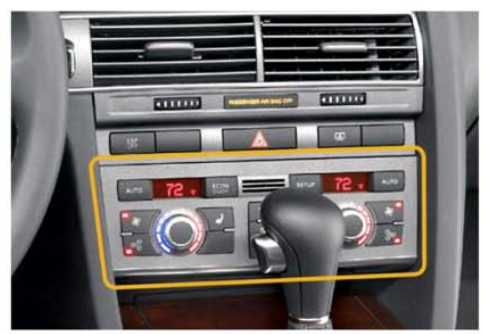

Sample E

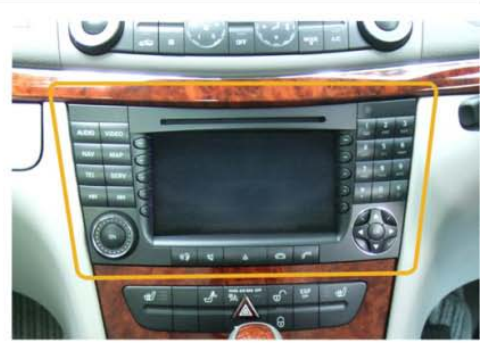

Sample C

Fig 1: Switch samples as assessed in context of the vehicle interior. For clarity the specific units have been highlighted, as they were during the research event.

The interior styling and feature content of the chosen vehicles dictated that it was not possible to have exactly comparable products from aesthetic or functional points of view. For example, vehicles 'B' and ' $E$ ' had LCD screens integrated into the dashboard, which were operated by central rotary input controllers. Because of this, the push-switches assessed in these samples were the ventilation controls. It should be noted however that conceptually, all the samples feature important, regularly used controls, and from our collaborating partners it is also known that harmony in the feel of switches throughout a car is something that automotive development teams strive for. These factors together with a careful sampling strategy have been designed to minimise data variance due to aesthetic differences between the samples.

\subsection{Data collection and experimental procedure}

The event took place in a UK location with no particular brand associations. Within the main room there was a separate screened off area where the out of context 'on-bench' assessment was conducted.

Participants separately assessed the feel of push-switches either seated inside the cars (in-context), or with the samples on a bench (out of context), and the two conditions were counterbalanced to minimise order effects. The assessment tasks carried out under each condition were identical; participants were first asked to spend approximately 10 minutes familiarising themselves with the feel of the switch operation on all the samples before starting to assess them individually on a series of semantic differential rating scales, followed by hedonic tests. This was to familiarise themselves with the range of different haptic characteristics present, and help define the extremes of the switch-feel domain. Several sessions were run over the course of two days, with groups of up to ten participants in each. The samples were assessed in a random order.

The semantic differential technique was developed by Osgood et al. (1957) as a method of measuring connotative meaning in language concepts. It is also commonly used to measure perceived impressions of products, services, and brands. The method involves participants rating their impressions on a series of 7 point Likert scales labelled ‘extremely' - ‘quite' - 'slightly' - 'neutral' - 'slightly' - ‘quite' - ‘extremely’, 
and anchored at each end with bipolar adjectives. In this study, participants rated their perception of the 'feel of the automotive push-switch operation' on eleven scales, which had been previously developed and used in a similar automotive switch study with Sports Utility Vehicles (Wellings et al., 2008). During the scale development work, it was clear that participants perceived the concept of switch-feel to encompass more variables than just those directly related to the sense of touch. So, in keeping with the holistic approaches of the research it was thought more appropriate not to restrict participants to responding in such narrow terms, hence the selected adjectives also relate to visual and auditory aspects of switch-feel. An alternative expression of 'switch-feel' could thus be presented as 'perceived haptic quality’. Table 2 lists the adjectives used.

During the assessment it was emphasised that the focus should be on the 'feel' of the switches, and not the whole vehicle interior. Hedonic data was collected using a ten point rating scale measuring the level of the liking, where 1 = dislike switch-feel, and 10 = like switch-feel. Participants also had to choose one set of switches they most preferred the feel of, and one set they least preferred the feel of, and then give qualitative reasons for their choices. During the assessment, participants were not allowed to talk to each other - especially during the on-bench part where the switch-packs were unbranded and there was a risk of identifying them to others.

Table 2: Bipolar adjective pairs used in semantic differential rating tasks

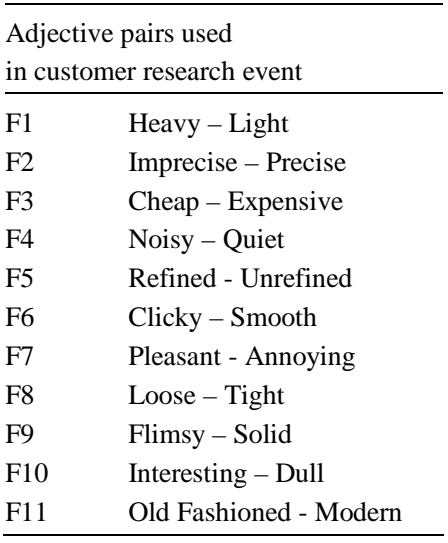

\subsection{Data analysis strategy}

The nonparametric Friedman test with a post hoc multiple-comparison procedure (Daniel, 1990) was used to investigate whether there are differences in the participants' overall responses for the different switch samples using ranked hedonic data, and the semantic differential ratings data. In addition, the categorical preference data was subjected to a chi-square goodness of fit test to check whether the choice frequency of the most (and also least) p referred samples are statistically equal. The impact that the contextual surroundings of the assessment had on hedonic rating scores was investigated using the Wilcoxon signed ranks test, which compares ranked data from the in-car and on-bench conditions.

Exploratory principal component analysis (PCA) with Varimax rotation was employed to summarise the semantic ratings data into a smaller number of latent dimensions from the initial eleven variables. A correlation matrix of the eleven variables was analysed for each sample, using participant's semantic rating scores as the observations. Factor scores were subsequently correlated with hedonic ratings to show how each switch sample differed. 
The qualitative preference data has been analysed through content analysis (Krippendorff, 2004a; Silverman, 2006) providing a quantitative indication of importance of the varying concepts integral to switch-feel preference.

The analysis of the hedonic tests and factor analyses used data solely from the in-context assessments, whereas both in-context and out of context data sets were compared when investigating the influence of assessment surroundings. The qualitative data was analysed as a combined set of data from both conditions.

\section{Results}

\subsection{Hedonic tests for the overall liking of switch samples}

The question of whether there is a difference in the overall degree of liking for the perceived haptic characteristics of the switches has been addressed through hedonic tests. A preliminary exploration of the hedonic rating histograms showed a wide range of responses given for each switch sample. The median rating scores ordered from most to least liked in terms of the feel of the switches were: sample ' $A$ ' $=9$, sample ' $C$ ' $=8$, sample ' $D$ ' $=6.5$, sample ' $E$ ' $=5$, sample ' $B$ ' $=2$; thus, sample 'A' switches were liked the most, and sample ' $\mathrm{B}$ ' switches were clearly liked the least. The distributions all exhibited nonnormality, (Shapiro-Wilks test, $p<0.01$ for all samples), with visibly skewed distribution for samples 'A', 'B', and ' $\mathrm{C}$ '.

The results of the Friedman Test show significance beyond the 1\% level (Chi squared (4) = 217.0; $p<0.01$ ), indicating that within the five switch samples at least one of the median ratings scores is significantly different from the others. A 'Least Significant Difference' post hoc test has then been used to ascertain specifically where the differences lay.

With the familywise error $\alpha$ set as 0.05 , the corresponding z score $=2.81$. The 'least significant difference' in the sums of ranks is thus calculated as 62.1. Pairwise differences exceeding this value are deemed to be significant, and Table 3 shows that significant differences were noticeable between all switches apart from 'A'-'C'. This provides evidence that as a group, drivers/owners of luxury saloon cars have a different degree of overall liking for individual switches. This is important to know as a prerequisite to allocating product development funds in the pursuit of better perceived switch-feel. 
Table 3: Post hoc analysis showing significant differences in hedonic scores for in-car assessments

\begin{tabular}{ll}
\hline $\begin{array}{l}\text { Comparison pairs } \\
\text { of switches }\end{array}$ & $\begin{array}{l}\text { Absolute difference in } \\
\text { sum of ranks (in-car) }\end{array}$ \\
\hline 'A' - 'B' & $=288^{\mathrm{a}}$ \\
'A' - 'C' & $=55.5$ \\
'A' - 'D' & $=128^{\mathrm{a}}$ \\
'A' - 'E' & $=191^{\mathrm{a}}$ \\
'B'- 'C' & $=232.5^{\mathrm{a}}$ \\
'B'- 'D' & $=160^{\mathrm{a}}$ \\
'B'- 'E' & $=97^{\mathrm{a}}$ \\
'C'- 'D' & $=72.5^{\mathrm{a}}$ \\
'C'- 'E' & $=135.5^{\mathrm{a}}$ \\
'D' - 'E' & $=63^{\mathrm{a}}$ \\
\hline
\end{tabular}

Ties are assigned a mean rank position

${ }^{\text {a }}$ Significant differences with familywise error $\alpha=0.05$ $(\mathrm{LSD}=62.1)$

Fig 2 shows the frequency counts for the most and least preferred choice of switch in terms of perceived haptic quality. The absolute scores clearly show that sample ' $A$ ' has the most preferred switch-feel $(+59)$, and sample 'B' the least preferred (-67), with no one at all considering the latter to have the best feeling switches. For both choice tests, the Chi Square results are significant (most preferred: $\chi^{2}=71.22, p<$ 0.01, least preferred: $\chi^{2}=156.90, p<0.01$ ). This shows that participants are not choosing the samples with equal frequency, and therefore they are not equally preferred in terms of the feel of their switches. The rank order of the net differences in frequency counts also mirrors that given in the hedonic ratings showing consistency in hedonic opinions by the participants.

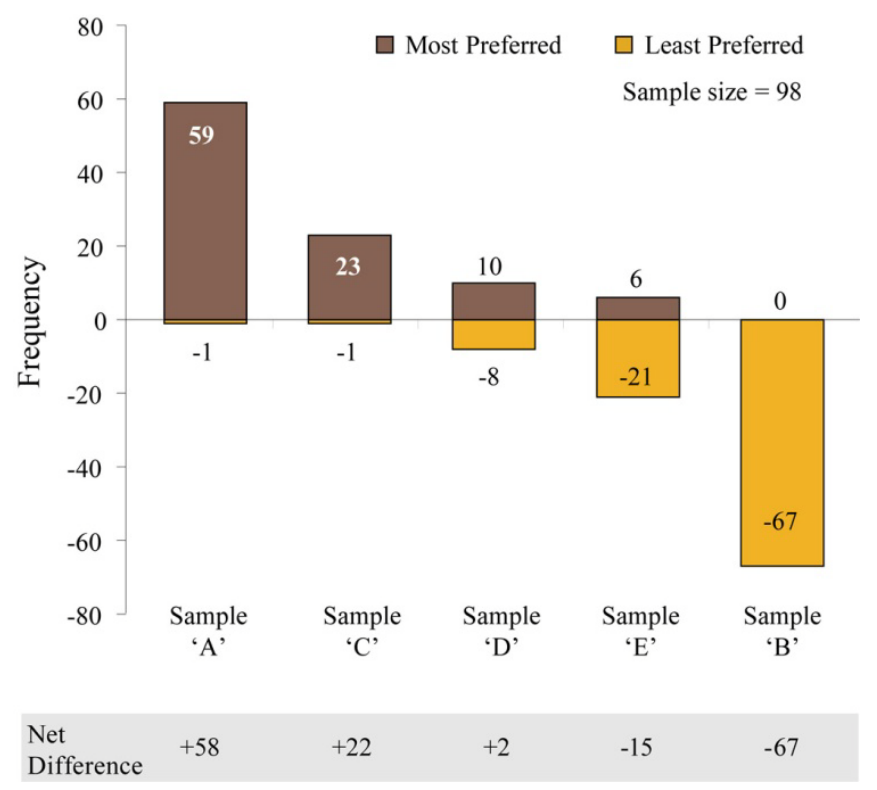


Fig 2: Absolute frequency counts of most and least preferred switch-feel (in-car assessment) together with net differences

\subsection{Comparing in-context (in-car) and out of context (on-bench) hedonic assessments}

Table 4 shows the median hedonic scores for both in-car and on-bench tests. Although the Wilcoxon signed-ranks test does not directly use the median scores to identify significant differences, it serves to illustrate the consistency in order of overall liking between the two conditions.

Table 4: Rank order of median hedonic test scores assessed in-car and on-bench

\begin{tabular}{lcc}
\hline & \multicolumn{2}{c}{ Median hedonic rating scores } \\
\hline Rank order & In-car & On-bench \\
\hline & & \\
Sample 'A' & 9 & 9 \\
Sample 'C' & 8 & 7 \\
Sample 'D' & 6.5 & 6 \\
Sample 'E' & 5 & 5 \\
Sample 'B' & 2 & 2 \\
\hline
\end{tabular}

Note: The Wilcoxon signed ranks test does not use plain median values to calculate significant differences

Table 5 shows the results from the Wilcoxon signed-ranks test. It can be seen that the difference between the sum of the ranked scores for the in-car assessment and the on-bench assessment was statistically significant beyond the $5 \%$ level for sample ' $\mathrm{B}$ '; the scores for the sample ' $\mathrm{C}$ ' switches were also close to significance. The differences in scores for the other three switches were not significant. From these results we can conclude that the surroundings the assessment took place in does appear to make a difference to the hedonic scores given, but that the effects are not consistent across the samples. Despite these differences, the order of overall liking as reported in Table 4 has remained the same. Taking these results in isolation, it appears that the expense of hiring vehicles can be saved, and conducting a similar assessment on a bench may yield accurate enough results for correct NPD decisions to be made. The literature backing this view up however is somewhat inconclusive. Boutrolle et al. (2007) reviewed a number of studies using either a laboratory setup or in-home testing (analogous to in-context), stating that "most studies clearly show the result of a hedonic test changes depending on the chosen methodology, but overall there is no consensus about the way in which it affects the results.” To be confident of having good repeatability further research is needed to investigate the impact of environmental factors on such results.

Table 5: Wilcoxon signed ranks test results for push-switch hedonic ratings

\begin{tabular}{llccc}
\hline & & $\begin{array}{c}\text { Test statistic } \\
\text { W }\end{array}$ & Z & $\begin{array}{c}\text { Exact Sig. } \\
\text { (2-tailed) }\end{array}$ \\
\hline Sample 'A' & On-bench - In-car & 623 & -1.25 & .22 \\
Sample 'B' & On-bench - In-car & 632 & -2.10 & $.04^{\text {a }}$ \\
Sample 'C' & On-bench - In-car & 947 & -1.76 & .08 \\
Sample 'D' & On-bench - In-car & 1366 & -.32 & .76 \\
Sample 'E' & On-bench - In-car & 1139 & -.21 & .83 \\
\hline
\end{tabular}

${ }^{\text {a }}$ significant difference $(\mathrm{p}<0.05)$ 


\subsection{Characteristics of switch-feel}

An exploratory Principle Components Analysis (PCA) has been carried out on the semantic differential rating data for each switch sample in order to reduce the initial eleven variables to fewer latent factors. It is also a useful method to investigate in more detail the differences in how the samples were perceived.

Firstly the correlation matrices were examined to ensure they had sufficient correlations $>0.3$, and were suitable for treatment with a PCA. Overall it was found there was enough correlation between the variables in each sample; Bartlett's test of sphericity was significant $(p<0.01)$ for each sample, and Kaiser-Mayer Olkin measures of sampling adequacy were all greater than 0.7. Certain individual variables however showed poor correlation with others. For the sample 'A' switch data, variables F1 (Heavy-Light) and F5 (Refined-Unrefined) had no correlations $>0.3$. In the sample ' $E$ ' data, F1 also had no correlations $>0.3$.

A number of analyses were run, extracting between two and five factors, and including different variables in the correlation matrix before arriving at the following conclusions. Three factor solutions were found to result in the simplest interpretation for all the samples, and each sample's data benefited from excluding the variable F1 (Heavy-Light), as suggested by the lack of correlations in the initial matrix. The rotated factor loading matrices are detailed in Tables 6 to 10, where the total variance explained for each solution is shown to be: sample 'A': $59.1 \%$, sample 'B': 62.5\%, sample 'C': 64.2\%, sample 'D': 70.5\%, sample ' $E$ ' $65.8 \%$. For this sample size of 98 participants, factor loadings that are practically, as well as statistically significant have been calculated as those greater than 0.512 (two times the standard error of the correlation coefficient at $\alpha=0.01$, two tailed test), (Stevens, 2002). Loadings less than 0.4 are not shown in the factor matrices to aid interpretation.

It seems that a general perceptual model used by the participants to assess the feel of push-switches may exist, as there is a reasonable degree of similarity in how the variables within the extracted components have clustered - however differences do exist. In the analyses of the samples ' $B$ ', ' $C$ ', ' $D$ ' and ' $E$ ' data, the first factor comprises variables describing the affective, or emotional responses of the participants to the feel of the switches - for example Dull-Interesting, Unrefined-Refined, or Annoying-Pleasant. This factor has been named 'Image', reflecting aspects of perceived meaning. The second factor is loaded most highly by variables Loose-Tight and Flimsy-Solid, although Imprecise-Precise also loads, but less predictably. These adjectives suggest a more tangible component, where the degree of free-play in the switches, and solidity of construction are influential criteria, and the factor has therefore been named 'Build Quality'. The third factor is commonly loaded by the variables Clicky-Smooth and Noisy-Quiet. This is named 'Clickiness', which appears to be a term that can be interpreted from both an auditory and haptic perspective. The results for the sample ' $A$ ' vary somewhat, and the resulting factor structure seems to reflect a different perceptual model, as there is not such a clear delineation between the Build Quality and Clickiness factors. Instead, the third factor is more closely defined by the affective connotations of usage, as it is loaded by the variables Unrefined-Refined, and Annoying-Pleasant. 
Table 6: Sample 'A' rotated factor loadings. Variable $F 1$ removed from calculation because of low correlations.

\begin{tabular}{lccc}
\hline & \multicolumn{3}{c}{ Sample 'A' Factor Loadings } \\
\hline Semantic pairs & $\begin{array}{c}\text { Factor 1 } \\
(23.4 \%)\end{array}$ & $\begin{array}{c}\text { Factor 2 } \\
(19.4 \%)\end{array}$ & $\begin{array}{c}\text { Factor 3 } \\
(16.2 \%)\end{array}$ \\
\hline Cheap-Expensive & .818 & & \\
Old Fashioned-Modern & .795 & & \\
Dull-Interesting & .597 & & \\
Noisy-Quiet & .577 & & \\
& & & \\
Loose-Tight & & .735 & \\
Flimsy-Solid & & .732 & \\
Imprecise-Precise & & .618 & .815 \\
Clicky-Smooth & .445 & .460 & $\mathbf{. 8 0 0}$ \\
\hline
\end{tabular}

${ }^{\mathrm{a}}$ Total variance accounted for by 3 factor solution $=59.1 \%$

${ }^{\mathrm{b}}$ Significant loadings $>0.512$ highlighted in bold

${ }^{\mathrm{c}}$ Factor loadings $<.4$ are not shown

Table 8: Sample 'C' rotated factor loadings. Variable $\mathrm{F} 1$ removed from calculation because of low correlations.

\begin{tabular}{|c|c|c|c|}
\hline \multirow[b]{2}{*}{ Semantic pairs } & \multicolumn{3}{|c|}{ Sample 'C' Factor Loadings ${ }^{\text {a, b, c }}$} \\
\hline & $\begin{array}{c}\text { Image } \\
(22.9 \%)\end{array}$ & $\begin{array}{c}\text { Build Quality } \\
(21.0 \%)\end{array}$ & $\begin{array}{c}\text { Clickiness } \\
(20.3 \%)\end{array}$ \\
\hline Unrefined-Refined & .817 & & \\
\hline Annoying-Pleasant & .804 & & \\
\hline Dull-Interesting & .767 & & \\
\hline Old Fashioned-Modern & & .776 & \\
\hline Flimsy-Solid & & .749 & \\
\hline Loose-Tight & & .655 & \\
\hline Cheap-Expensive & .410 & .525 & .475 \\
\hline Noisy-Quiet & & & .786 \\
\hline Clicky-Smooth & & .408 & .714 \\
\hline Imprecise-Precise & & & .685 \\
\hline
\end{tabular}

Table 7: Sample 'B' rotated factor loadings. Variable F1 removed from calculation because of low correlations.

\begin{tabular}{|c|c|c|c|}
\hline \multirow[b]{2}{*}{ Semantic pairs } & \multicolumn{3}{|c|}{ Sample 'B' Factor Loadings a, b, c } \\
\hline & $\begin{array}{l}\text { Image } \\
(24.3 \%)\end{array}$ & $\begin{array}{c}\text { Build Quality } \\
(20.9 \%)\end{array}$ & $\begin{array}{c}\text { Clickiness } \\
(17.4 \%)\end{array}$ \\
\hline Unrefined-Refined & .768 & & \\
\hline Annoying-Pleasant & .761 & & \\
\hline Dull-Interesting & .698 & & \\
\hline Cheap-Expensive & .572 & & \\
\hline Loose-Tight & & .893 & \\
\hline Flimsy-Solid & & .825 & \\
\hline Imprecise-Precise & .478 & .617 & \\
\hline Clicky-Smooth & & & .796 \\
\hline Noisy-Quiet & & & .687 \\
\hline Old Fashioned-Modern & & & .607 \\
\hline
\end{tabular}

${ }^{\mathrm{a}}$ Total variance accounted for by 3 factor solution $=62.5 \%$

${ }^{\mathrm{b}}$ Significant loadings $>0.512$ highlighted in bold

${ }^{\mathrm{c}}$ Factor loadings $<.4$ are not shown

Table 9: Sample 'D' rotated factor loadings. Variable F1 removed from calculation because of low correlations.

\begin{tabular}{|c|c|c|c|}
\hline \multirow[b]{2}{*}{ Semantic pairs } & \multicolumn{3}{|c|}{ Sample 'D' Factor Loadings ${ }^{\text {a, b, c }}$} \\
\hline & $\begin{array}{l}\text { Image } \\
(29.8 \%)\end{array}$ & $\begin{array}{c}\text { Build Quality } \\
(22.6 \%)\end{array}$ & $\begin{array}{c}\text { Clickiness } \\
(18.1 \%)\end{array}$ \\
\hline Annoying-Pleasant & .858 & & \\
\hline Unrefined-Refined & .801 & & \\
\hline Dull-Interesting & .796 & & \\
\hline Old Fashioned-Modern & .644 & & \\
\hline Cheap-Expensive & .604 & .543 & \\
\hline Flimsy-Solid & & .836 & \\
\hline Loose-Tight & & .778 & \\
\hline Imprecise-Precise & & .724 & \\
\hline Clicky-Smooth & & & .833 \\
\hline Noisy-Quiet & & & .812 \\
\hline
\end{tabular}


Table 10: Sample 'E' rotated factor loadings. Variable F1 removed from calculation because of low correlations.

\begin{tabular}{lccc}
\hline & \multicolumn{3}{c}{ Sample 'E' Factor Loadings ${ }^{\text {a, b, c }}$} \\
\hline Semantic pairs & $\begin{array}{c}\text { Image } \\
(29.3 \%)\end{array}$ & $\begin{array}{c}\text { Build Quality } \\
(19.2 \%)\end{array}$ & $\begin{array}{c}\text { Clickiness } \\
(17.2 \%)\end{array}$ \\
\hline Dull-Interesting & $\mathbf{. 8 4 0}$ & & \\
Unrefined-Refined & $\mathbf{7 6 0}$ & & \\
Cheap-Expensive & .754 & & \\
Annoying-Pleasant & .714 & & \\
Old Fashioned-Modern & .504 & & \\
& & & \\
Loose-Tight & & $\mathbf{8 9 1}$ & \\
Flimsy-Solid & & $\mathbf{6 7 9}$ & $\mathbf{. 9 1 2}$ \\
Imprecise-Precise & & & $\mathbf{. 8 7 6}$ \\
\hline
\end{tabular}

${ }^{\mathrm{a}}$ Total variance accounted for by 3 factor solution $=65.8 \%$

${ }^{\mathrm{b}}$ Significant loadings $>0.512$ highlighted in bold

${ }^{\mathrm{C}}$ Factor loadings $<.4$ are not shown

Correlating factor scores with hedonic ratings (Table 11) shows which perceived characteristics of switch-feel are associated with customers' hedonic responses. The results for the samples ' $\mathrm{A}$ ' and ' $\mathrm{B}$ ' show the strongest significant $(p<0.01)$ correlations with the first factor. They were also the most and least preferred samples, thereby indicating the greatest agreement in opinion amongst participants. The results show that for sample ' $\mathrm{A}$ ' switches, liking is associated most strongly with their expensive, modern, interesting, and quiet characteristics. In the case of switch sample ' $\mathrm{B}$ ', the characteristics unrefined, annoying, dull and cheap associated most strongly. For the other three samples, their second factor also correlates significantly $(p<0.01$ ) with liking, meaning that the variables Loose-Tight, FlimsySolid, and Imprecise-Precise are influential criteria.

Table 11: Correlations between hedonic rating scores and PCA factor scores. N.B. Rotated factors are orthogonal with near zero correlations and are not shown.

\begin{tabular}{lccc}
\hline \multicolumn{4}{c}{ Correlation coefficients } \\
\hline $\begin{array}{c}\text { factor score } 1 \\
\text { (Image) }\end{array}$ & $\begin{array}{r}\text { factor score } 2 \\
\text { (Build Quality) }\end{array}$ & $\begin{array}{c}\text { factor score } 3 \\
\text { (Clickiness) }\end{array}$ \\
\hline Sample 'A' hedonic rating & $.590^{\mathrm{a}}$ & $.216^{\mathrm{b}}$ & .076 \\
Sample 'B' hedonic rating & $.586^{\mathrm{a}}$ & $.214^{\mathrm{b}}$ & $.283^{\mathrm{a}}$ \\
Sample 'C' hedonic rating & $.370^{\mathrm{a}}$ & $.433^{\mathrm{a}}$ & .184 \\
Sample 'D' hedonic rating & $.535^{\mathrm{a}}$ & $.447^{\mathrm{a}}$ & $.283^{\mathrm{a}}$ \\
Sample 'E' hedonic rating & $.479^{\mathrm{a}}$ & $.443^{\mathrm{a}}$ & .167 \\
\hline a Correlation is significant at the 0.01 level (2-tailed). \\
b Correlation is significant at the 0.05 level (2-tailed).
\end{tabular}


Similar patterns to those revealed by factor analysis can be seen when the qualitative reasons why participants 'most' or 'least' preferred the feel of a switch are analysed through content analysis (Krippendorff, 2004a).

The data has been divided up into discrete concepts to give 251 individual 'most preferred' comments, and 212 'least preferred' comments. Twenty eight positive and thirty one negative categories were defined in an exploratory process, to which the comments were then assigned by two of the authors. Comparison between these two sets of coded data showed inter-coder agreement of $91.2 \%$.

It can be seen in Fig 3 that the largest numbers of comments fall into the 'praise' category (13\%), which are straightforward affirmations of a product, e.g. 'I like the feel'. Where specific reasons are given, 'ease of use' is the second most frequent reason given (10\%), followed by smoothness (9\%), modernity (9\%), precision (8\%) and solidity (6\%). Another usability criteria appearing in the top ten is layout and spacing (5\%).

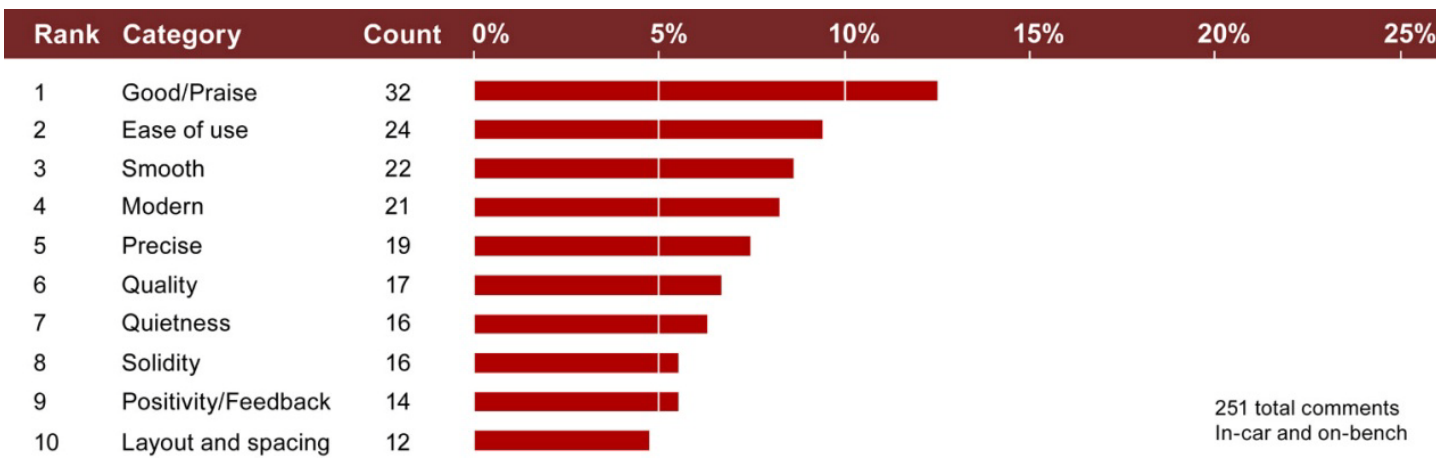

Fig 3: Top 10 categories of positive comments about customers' most preferred feeling push-switch

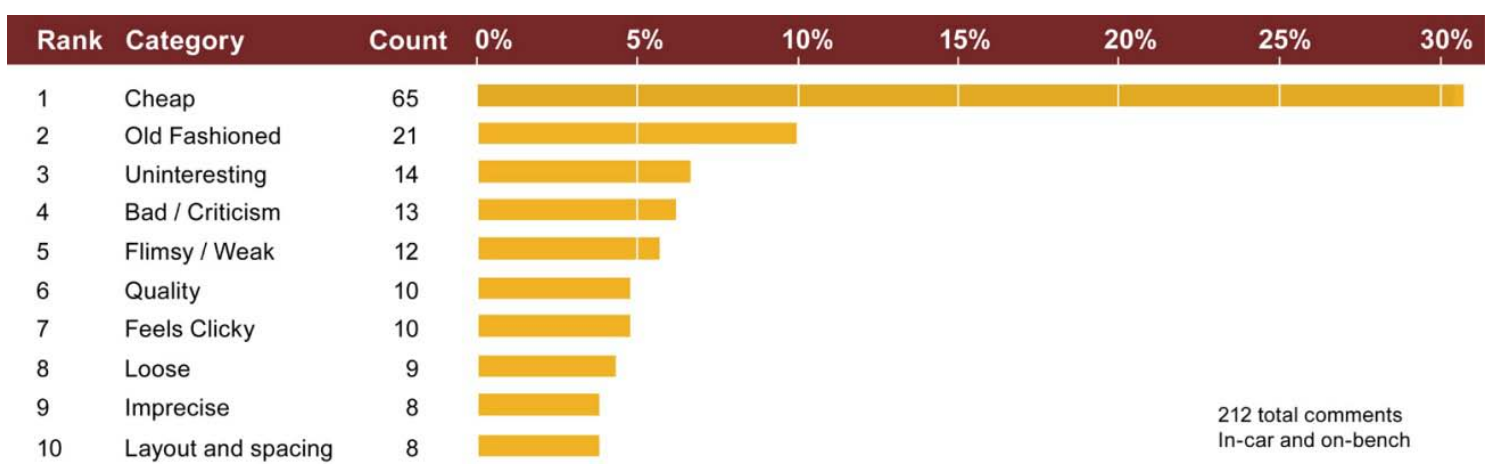

Fig 4: Top 10 categories of negative comments about customers’ least preferred feeling push-switch

In Fig 4 it can be seen that switches feeling 'cheap' dominated the reasons given for least preferring a particular sample (31\%). This also featured in factor one from the sample 'B' PCA. Other reasons cited were the switches being 'old-fashioned' (10\%), uninteresting (7\%), and 'flimsy/weak' (6\%). To gain more insight into what the participants mean by 'cheap', the context surrounding the use of the phrase was analysed in more depth. It has been found that the most commonly occurring comments cited 
alongside 'cheapness' related to the switches being 'old-fashioned', noisy and clicky, generally poor quality, and flimsy/weak. This indicates that cheapness is a composite of the other negative categories.

\section{Discussion}

\subsection{Resource allocation and value for money}

Whether the customers' express differences in their overall liking for the haptic quality of different pushswitches, and also whether there is any consensus in what these qualities are is relevant for automotive Original Equipment Manufacturers (OEMs) because at a organisational level, there is always competition for development budgets, and knowing whether it is worth allocating resources to develop better switches and controls is vital.

Statistically significant differences in all the pairwise comparisons of the hedonic ratings apart from samples 'A - C' clearly show that the participants can perceive some meaningful differences between the switches. The participants are also able to easily express a most, and least preferred sample in terms of haptic quality. The data show clearly that the sample ' $\mathrm{A}$ ' was chosen by more than twice as many people compared to the next best, which was sample ' $\mathrm{C}$ '. Even though these two samples were not significantly different based on their hedonic ratings, the most preferred choice data suggests there is a genuine difference in the degree of liking that luxury saloon customers have for them. It is useful for both designers and engineers to have this kind of empirical data available when making product development decisions because it can help to reduce the subjectivity, and understand the view of the customer better. In this product sector example there appears to be broad agreement amongst the participants on which switch haptics were liked, and which were disliked (see the frequency counts in Fig 2). The practical implication of this finding is that there are some as yet undefined haptic characteristics of push-switches, which in a certain combination can engender almost universal preference. The next stage is to try and identify what these characteristics are, and how they interrelate.

\subsection{Underlying characteristics of perceived switch haptics}

If specifications relating to the haptic elements of HMI are to be developed, a deeper understanding of the interaction experience is necessary. A factor analysis of the semantic differential data was chosen as a way to uncover the customers' tacit opinions.

The main issue in the analysis was whether to extract three or four components. The five samples were each perceived differently, and hence had some differences in their solutions, but there were sufficient similarities to convince the authors that a common underlying factor structure does exist. This backs up previous research by the authors into perception of switch haptics in luxury SUVs, which also yielded a three factor solution (Wellings et al., 2008). In that research, the factors were named 'Affective', Robustness and precision', and Silkiness, but they were largely loaded by the same variables as here.

What has also become apparent is that the semantic scales need to be refined and probably increased in number to get clearer factors. It is necessary with factor analyses to make sure that there are sufficient variables being analysed, and Fabrigar et. al (1999) recommend that this should be at least 3 to 5 times the number of expected common factors. In this research, there are eleven measured variables, which looks adequate if three factors are extracted, but insufficient to give a fourth factor that is not uniquely loaded 
by a single variable. A suggestion for future research of this type would be to increase the number of variables to between fifteen and twenty.

As well as the number of variables, it is important that their meaning resonates with the overall construct being investigated. As described in the results, the Heavy-Light scale had particularly low correlations, and should probably be removed where the operational feel of switches is the construct being assessed. Questions have also been raised over how reliable the ‘Old Fashioned-Modern' variable is. It loads significantly on the first factor for samples ' $A$ ' and ' $D$ ', the second factor for sample ' $C$ ', and the third factor for sample ' $\mathrm{B}$ '. It also does not load significantly on any factor for sample ' $E$ '. The variable CheapExpensive also shows inconsistencies as it loads multiple factors for the samples ' $\mathrm{D}$ ' and ' $\mathrm{C}$ ', however in the qualitative data, opinion is unequivocal as 'Cheapness' is the most commonly cited reason (30.7\%) for disliking switch-feel. It is thought here that the concept of expensive feeling switches is hard to grasp, and that when applied to automotive switches, does not represent the opposite of cheapness. The refinement of these assessment scales is something that needs to be addressed in order to improve internal validity and reliability for future studies of this type.

\subsection{HMI interaction and models of product experience}

In the introduction, different theoretical models for product interaction were highlighted from Desmet and Hekkert (2007), and Jordan (2000). Whilst not an attempt to review the range of different frameworks and theoretical models that exist, these authors are commonly referenced, and represent a suitable starting point for a discussion. If, as described, product interaction adheres to any of the proposed theoretical models, the factor analysis should give evidence for their validity. Although the findings presented do not explicitly backup a specific model, they do add empirical data to the debate, and show characteristics in common with the existing propositions. The authors believe this provides some evidence of their collective veracity, and justification for more research.

The first extracted factor from the switch haptics data is named 'Image', and is analogous to Desmet and Hekkert's 'Experience of Meaning' component, which describes the personal meanings, or symbolic significance we attach to products. The meanings conveyed by the notion of a refined, interesting and modern switch can also be conveyed as 'luxury', which is similar to the broader emotional component of pleasurable product use that Jordan defines; i.e. "The emotional, hedonic and practical benefits associated with products and services”.

The second factor 'Build Quality', describes the part of an appraisal process, where the perceived quality of the switch is compared against personal expectations. In Desmet and Hekkert's model, the consequence of this mental process are emotions, and these are represented by the 'Emotional Experience' component. This component is also synonymous with Jordan's 'Psycho pleasure' (from Tiger's 'Four Pleasures', in Tiger, 2000), which is described as "the emotional reactions engendered through the experience of using a product”.

The third factor, 'Clickiness' reflects opinions connected to the auditory and haptic senses. Desmet and Hekkert categorise these sensory components of experience as 'Aesthetic pleasure'. This is similarly identified by Jordan within his ‘four pleasures’ framework as 'Physio pleasure’.

It has become clear through content analysis of the qualitative data, that in addition to the haptic and perceived quality aspects of the vehicle HMI, luxury saloon customers are also very sensitive to usability criteria. This information was given despite the absence of questions directly referring to usability, and 
highlights the need to include this important concept in theoretical user experience models. It also shows how in the minds of customers usability is not divorced from perceived quality, haptics, or visual aesthetics. Because of this, it does not make sense to try and address these parts of the design in separate product development teams.

\section{Conclusions}

Customers of luxury saloon cars have been shown to be able to express differences in their overall liking for automotive push-switches based on their haptic qualities. The median hedonic rating scores for five samples were significantly different for all but one of the pairwise comparisons (familywise error $\alpha=$ 0.05). In addition, a most-least preferred choice test indicated clear preferences for the sample ' $\mathrm{A}$ ' switches, and a clear dislike for Sample 'B' switches. The issue of assessment context was addressed by comparing hedonic scores from a task conducted within a car, with one conducted in a controlled central location. Here, there were significant differences $(p<0.05)$ for one of the samples, but not for the other four, showing that an effect is present, but not universal.

Through factor analysis, the perceived characteristics of switch haptics have been shown to be represented by three independent factors in each of the five samples. These explain between $59 \%$ and $71 \%$ of the total variance, and have been defined as 'Image', 'Build quality', and 'Clickiness'. These factors are compared with theoretical models of product interaction as proposed by Desmet and Hekkert (2007), and Jordan (2000), and shown to exhibit similarities in their components. A content analysis of the qualitative customer opinions has shown that customers do not consider switch-feel solely in terms of haptic criteria. They also inherently link it to perceptions of usability, visual appearance, and sound quality.

\section{Acknowledgements}

The authors would like to thank Advantage West Midlands for funding the collection of the data through the Premium Automotive Research and Development programme. We would also like to thank the Engineering and Physical Sciences Research Council for funding the Warwick Innovative Manufacturing Research Centre, which has enabled our research to be furthered. 


\section{References}

Adams-Bigelow, M., and Griffin, A., 2005. Product Development Cycle Time and Success: New Results from PDMA’s Comparative Performance Assessment Study. In: Product Development and Management Association International Conference, October San Diego, CA.

Benson, R., MacRury, I., and Marsh, P., 2007. The secret life of cars and what they reveal about us. London, Not Actual Size.

Bonapace, L., 2002. Linking product properties to pleasure: the sensorial quality assessment method SEQUAM. In Green, W. \& Jordan, P. (Eds.), Pleasure with products: beyond usability. London, Taylor \& Francis, pp. 189-217.

Boutrolle, I., Delarue, J., Arranz, D., Rogeaux, M., and Köster, E. P., 2007. Central location test vs. home use test: Contrasting results depending on product type. Food Quality and Preference. 18 (3), 490-499.

Burnett, G., and Porter, J., 2001. Ubiquitous computing within cars: designing controls for non-visual use. International Journal of Human-Computer Studies. 55 (4), 521-531.

Carbonaro, S., and Votava, C., 2005. Paths to a new prosperity. The Nordic Textile Journal, 71-85.

Cooper, R., Edgett, S., and Kleinschmidt, E., 2004. Benchmarking best NPD practices - III. ResearchTechnology Management. 47 (6), 43-55.

Cooper, R., and Kleinschmidt, E., 1991. New Product Processes at Leading Industrial Firms. Industrial Marketing Management. 20 (2), 137-147.

Daniel, W. W., 1990. Applied nonparametric statistics, 2nd ed. Boston, PWS-KENT Pub.

Desmet, P., and Hekkert, P., 2007. Framework of Product Experience. International Journal of Design. 1 (1), 57-66.

DTI. 2004. Innovation through people-centred design - lessons from the USA. In: Wakeford, N. (Eds.), Global Watch Mission Report. Department of Trade and Industry, UK, URN 04/1863.

Eason, K., 1989. Information Technology and Organisational Change. London, Taylor and Francis.

Evans, S., and Burns, A., 2007. An investigation of customer delight during product evaluation: implications for the development of desirable products. Proceedings of the I MECH E Part B Journal of Engineering Manufacture. 221 (11), 1625-1638.

Fabrigar, L. R., Wegener, D. T., MacCallum, R. C., and Strahan, E. J., 1999. Evaluating the Use of Exploratory Factor Analysis in Psychological Research. Psychological Methods. 4 (3), 272-299.

Giboreau, A., Navarro, S., Faye, P., and Dumortier, J., 2001. Sensory evaluation of automotive fabrics: the contribution of categorization tasks and non verbal information to set-up a descriptive method of tactile properties. Food Quality and Preference. 12 (5-7), 311-322.

Griffin, A., 1997. PDMA research on new product development practices: Updating trends and benchmarking best practices. Journal of Product Innovation Management. 14 (6), 429-458.

Hassenzahl, M., 2005. Hedonic, emotional, and experiential perspectives on product quality. In Ghaouri, C. (Eds.), Encyclopedia of Human Computer Interaction, Idea Group, Hershey, PA

Hassenzahl, M., and Tractinsky, N., 2006. User experience - a research agenda. Behaviour \& Information Technology. 25 (2), 91 - 97. 
Hekkert, P., 2006. Design aesthetics: principles of pleasure in design. Psychology Science. 48 (2), 157172.

Helander, M., 1997. The human factors profession. In Salvendy, G. (Eds.), Handbook of Human Factors and Ergonomics. New York, John Wiley, pp. 3-16.

Hsu, S. H., Chuang, M. C., and Chang, C. C., 2000. A semantic differential study of designers' and users' product form perception. International Journal of Industrial Ergonomics. 25 (4), 375-391.

ISO. 1999. Human-centred design processes for interactive systems. International Organization for Standardization, ISO13407:1999.

Jetter, H.-C., and Gerken, J., 2006. A simplified model of user experience for practical application. In: Mørch, A., Morgan, K., Bratteteig, T., Ghosh, G. \& Svanaes, D. (Eds.), NordiCHI 2006: the 4th Nordic conference on Human-computer interaction: changing roles, Oslo, Norway. ACM Press, 106-111.

Jindo, T., and Hirasago, K., 1997. Application studies to car interior of Kansei engineering. International Journal of Industrial Ergonomics. 19 (2), 105-114.

Jordan, P., 2000. Designing pleasurable products : an introduction to the new human factors. London, Taylor \& Francis.

Kahn, K., Barczak, G., and Moss, R., 2006. Perspective: Establishing an NPD best practices framework. Journal of Product Innovation Management. 23 (2), 106-116.

Karat, J., and Karat, C. M., 2003. The evolution of user-centered focus in the human-computer interaction field. IBM Syst. J. 42 (4), 532-541.

Karlsson, B., Aronsson, N., and Svensson, K., 2003. Using semantic environment description as a tool to evaluate car interiors. Ergonomics. 46 (13-14), 1408-1422.

Kawazu, K., Kai, M., Koike, K., Imada, M., and Yasuda, K., 2000. Study of favorable feel paint quantifying the sense of touch for painted panels. In: SAE 2000 World Congress, March 6-9 Detroit, Michigan. 2000-01-1362.

Khalid, H. M., and Helander, M. G., 2004. A framework for affective customer needs in product design. Theoretical Issues in Ergonomics Science. 5 (1), 27 - 42.

Krippendorff, K., 2004a. Content analysis : an introduction to its methodology, 2nd ed. Thousand Oaks, CA., Sage.

Krippendorff, K., 2004b. Intrinsic motivation and human-centred design. Theoretical Issues in Ergonomics Science. 5 (1), 43 - 72.

Kumar, V., and Whitney, P., 2007. Daily life, not markets: customer-centered design. Journal of Business Strategy. 28 (4), 46-58.

Langerak, F., Hultink, E. J., and Griffin, A., 2008. Exploring Mediating and Moderating Influences on the Links among Cycle Time, Proficiency in Entry Timing, and New Product Profitability. Journal of Product Innovation Management. 25 (4), 370-385.

Leonard, D., and Rayport, J., 1997. Spark innovation through empathic design. Harvard Business Review. 75 (6), 102-113.

Light, A., 2006. Adding method to meaning: a technique for exploring peoples' experience with technology. Behaviour \& Information Technology. 25 (2), 175 - 187. 
MacDonald, A. S., 2001. Aesthetic intelligence: optimizing user-centred design. Journal of Engineering Design. 12 (1), 37-45.

Mauter, G., and Katzki, S., 2003. The application of operational haptics in automotive engineering. London, Touch Briefings. Available from: http://www.touchbriefings.com/cdps/cditem.cfm?cid=6\&nid=11, [Accessed 15 July 2008].

McLoone, H., 2003. Touchable objects: attributes applied to the design of computer input devices. Ergonomics. 46 (13-14), 1320-1331.

Moore, T. G., 1974. Tactile and kinaesthetic aspects of push-buttons. Applied Ergonomics. 5 (2), 66-71.

Nagamachi, M., 2002. Kansei engineering as a powerful consumer-oriented technology for product development. Applied Ergonomics. 33 (3), 289-294.

Osgood, C., Suci, G., and Tannenbaum, P., 1957. The measurement of meaning. Urbana,, University of Illinois Press.

Robinson, W. T., and Min, S., 2002. Is the first to market the first to fail? Empirical evidence for industrial goods businesses. Journal of Marketing Research. 39 (1), 120-128.

Silverman, D., 2006. Interpreting qualitative data : methods for analyzing talk, text, and interaction, 3rd ed. London ; Thousand Oaks, Calif., SAGE Publications.

Stanney, K., Maxey, J., and Salvendy, G., 1997. Socially-centered design. In Salvendy, G. (Eds.), Handbook of Human Factors and Ergonomics. New York, John Wiley, pp. 637-656.

Stevens, J., 2002. Applied multivariate statistics for the social sciences, 4th ed. Mahwah, N.J., Lawrence Erlbaum Associates.

Stone, H., and Sidel, J., 2004. Sensory evaluation practices, 3rd ed. London, Elsevier Academic Press.

Tiger, L., 2000. The Pursuit of Pleasure. Transaction Publishers.

VCA. 2001. European Type Approval for Automotive Systems and Components (Revision 7). Bristol, UK, Vehicle Certification Agency, VCA004.

Veryzer , R., and de Mozota, B., 2005. The impact of user-oriented design on new product development: An examination of fundamental relationships. Journal of Product Innovation Management. 22 (2), 128-143.

Wellings, T., Williams, M., A., and Pitts, M., 2008. Customer perception of switch-feel in luxury sports utility vehicles. Food Quality and Preference. 19 (8), 737-746.

Williams, M., and Kochhar, A., 2000. New product introduction practices in the British manufacturing industry. Proceedings of the Institution of Mechanical Engineers Part B-Journal of Engineering Manufacture. 214 (10), 853-863.

Yun, M. H., Han, S., Hong, S., and Kim, J., 2003. Incorporating user satisfaction into the look-and-feel of mobile phone design. Ergonomics. 46 (13-14), 1423-1440. 